\title{
Implementing Autonomy Support: Insights from a Montessori Classroom
}

\author{
Joyce Hwee Ling Koh (Corresponding author) \\ National Institute of Education, Nanyang Technological University, Singapore \\ 1 Nanyang Walk, Singapore 637616
}

Tel: 1-65-6790-3356 E-mail: joyce.koh@nie.edu.sg

Theodore W. Frick

Department of Instructional Systems Technology, Indiana University

W.W. School of Education, 201 N. Rose Avenue, ED2218

Bloomington, IN 47405, United States

Tel: 1-812-856-8460Ｅ-mail: frick@indiana.edu

\begin{abstract}
Extant research studies have found that autonomy support has a positive impact on the perceived competence and intrinsic motivation of students. However, few studies have investigated how autonomy supportive classrooms can be implemented. Montessori education is established upon the philosophy of helping each child attain self-mastery and independence. It emphasizes that students be given autonomy to engage freely with their learning environment. This case study of an upper-elementary Montessori classroom found that the Montessori philosophy of education guided how teachers used autonomy supportive strategies. Teachers supported student organizational autonomy by allowing them choice in terms of school work and work partners. They fostered cognitive autonomy by encouraging student independent thinking, encouraging self-initiation, and honoring students' voice. When implementing control, they acknowledged and respected student feelings, provided rationales for expected behavior, and suppressed criticism. Students surveyed rated themselves highly in terms of intrinsic motivation for schoolwork. Five guidelines are derived from this study to help teachers implement autonomy support in K-12 classrooms.
\end{abstract}

Keywords: Autonomy support, Self-Determination Theory, Montessori method, Intrinsic motivation 


\section{Introduction}

Autonomy refers to the ability for self-determination or self-governance of actions. Self-Determination Theory postulates that autonomy support in social contexts contributes to intrinsic motivation for action (Deci, Vallerand, Pelletier, \& Ryan, 1991). Empirical studies have also found that students' perceptions of teacher autonomy support were positively correlated to their intrinsic motivation for learning (Hardre \& Reeve, 2003; Standage, Duda, \& Ntoumanis, 2005; Valas \& Sovik, 1993). While the relationship between autonomy support and motivation for learning has been empirically proven, the practice of autonomy support in K-12 classrooms is still not well-understood (Ames, 1992; Stefanou, Preencevich, DiCintio, \& Turner, 2004; Urdan \& Turner, 2005).

Montessori education is established upon the philosophy of helping each child become a disciplined individual who is "master of himself, and can, therefore, regulate his own conduct when it shall be necessary to follow some rule of life" (Montessori, 1964, p. 86). Student autonomy is an important tenet of Montessori education as it is used to educate children to make responsible choices within a "prepared" learning environment (Lillard, 2005). Studies comparing children from Montessori schools and traditional schools found that Montessori children had higher intrinsic motivation for learning and achievement in state tests (Duax, 1989; Rathunde \& Csíkszentmihályi, 2005). Yet, children in traditional schools have reported a steady decline in intrinsic motivation for school from third grade through high school (Anderman \& Maehr, 1994; Harter, 1981; Lepper, Sethi, Dialdin, \& Drake, 1996). An analysis of Montessori teaching can shed light about practices that teachers use to foster autonomy and intrinsic motivation for learning.

\section{Aims of Study}

This qualitative case study explored teachers' strategies for autonomy support, and student intrinsic motivation in an upper-elementary Montessori classroom in the state of Indiana, USA. The research questions studied were:

a) What were the characteristics of teacher autonomy support in a Montessori classroom?

b) To what extent were students in a Montessori classroom intrinsically motivated to do school work?

Different examples of teacher autonomy support were derived through lesson observations, and corroborated with surveys of teachers' motivation styles and students' intrinsic motivation for schoolwork. The relevance of these observations for the development of motivation practices in K-12 classrooms is discussed.

\section{Theoretical Framework}

Autonomy has traditionally been equated to choice (Katz \& Assor, 2007). Choice was found to enhance autonomy and intrinsic motivation if it was perceived to be important to students' personal interests and goals (Assor, Kaplan, \& Roth, 2002; Cordova \& Lepper, 1996; Katz \& Assor, 2007; Reynolds \& Symons, 2001). Stefanou et al. (2004) argued that autonomy need not be synonymous with choice, and proposed that teachers can provide students with three 
types of autonomy: (1) organizational autonomy - ownership of learning environment, (2) procedural autonomy - ownership of the form of their work, and (3) cognitive autonomy ownership of learning. Among these three types of autonomy, Stefanou et al. found that cognitive autonomy support was most influential towards developing children's intrinsic motivation. This concurred with studies of autonomy supportive teachers who found that they tend to exhibit behaviors that encouraged students' involvement in learning. For example, they tend to listen more, give fewer directives, solicit student feedback regularly, allow student criticism of learning tasks, foster relevance, encourage student independent thinking, and respond more often to student's questions (Assor et al., 2002; Manouchehri, 2004 ; Reeve, Bolt, \& Cai, 1999).

Autonomy support was also contrasted with control, which was defined as external events that undermined one's autonomy. Extrinsic rewards, threats of punishments, imposed goals, competition, and high stakes testing were some types of events predominantly perceived as "controlling" (Deci \& Ryan, 2002). When students perceived teachers to be "directly controlling" by giving them frequent directives, interfering with their preferred pace of learning and not allowing independent opinions, it predicted higher levels of anger and anxiety (Assor, Kaplan, Kanat-Maymon, \& Roth, 2005).

Controlling events have often been associated with extrinsic motivation for action, and viewed as being "antagonistic" to intrinsic motivation (Vansteenkiste, Lens, \& Deci, 2006). Self-Determination Theory, however, posited humans to be organismic beings (Deci \& Ryan, 2000) with an innate tendency towards intrinsic motivation. Therefore, they were able to "transform socially sanctioned mores or requests into personally endorsed values and self-regulations" (Deci \& Ryan, p. 236). This process of internalization was theorized to occur across five states of motivation described by the Organismic Integration Theory (Deci \& Ryan, 2000; Deci et al., 1991; Ryan \& Connell, 1989; Ryan \& Deci, 2002): (1) External regulation - behaviors executed only upon initiation by external conditions. (2) Introjected regulation - behaviors not regarded as part of the integrated self, and therefore exhibited unwillingly even though they may not be initiated by external conditions. (3) Identified regulation - behaviors that were valued and accepted as part of self to some extent. (4) Integrated regulation - behaviors fully integrated with one's sense of self but still viewed as a means to satisfy an outcome dictated by external contingencies. (5) Intrinsic motivation behaviors deemed as fully autonomous and self-determined. When applied to an educational context, it implied that students are able to develop intrinsic motivation for school work by internalizing learning tasks that may not be "inherently interesting or enjoyable" (Ryan \& Deci, 2000, p. 55).

This process of internalization corresponds to the Montessori philosophy where children are treated as natural phenomenon to be observed and understood (Montessori, 1964). Children have autonomy to choose Works within a "prepared environment" that interests them (Hainstock, 1997, p. 81). Montessori teachers support student autonomy through a balance of observation and intervention. Children are left alone when they are interested and concentrating on their Works while teachers intervene to help them make good choices when they become unproductive and disinterested in their Works. This could involve helping them 
become interested in the Works they did not naturally choose, proposing options of new Works when they are ready, or disciplining them for disruptive behaviour (Lillard, 2005; Montessori, 1964). There is some evidence that such classroom practices are effective for fostering children's intrinsic motivation for learning. Rathunde \& Csíkszentmihályi (2005) studied 550 children from both Montessori and traditional schools, who rated their experiences for academic schoolwork eight times per day across a week. Statistical analysis found that the Montessori children posted significantly higher ratings for intrinsic motivation towards academic schoolwork. The authors proposed that this could be because Montessori classroom practices concurred with the postulations of contemporary motivation theories. These results show that Montessori teachers' practice of autonomy support could be effective for helping children internalize external motivations for schoolwork. Its concurrence with extant motivation theories is worthwhile of further investigation with qualitative methodologies where rich descriptions of classroom practices can be collected through naturalistic observation (Creswell, 1998). However, published qualitative studies of Montessori classroom practices are rare; even more so in terms of teacher autonomy support. This study therefore aims to address these gaps by exploring the characteristics of autonomy support in Montessori teaching through the lens of Self-Determination Theory.

\section{Methodology}

\subsection{Case selection}

The case study methodology is a qualitative method used for naturalistic study of a phenomenon within a bounded system (Creswell, 1998). In this study, a Montessori classroom was treated as the bounded system to analyze the phenomenon of teacher autonomy support. An upper elementary classroom within a Montessori school in the state of Indiana, USA was purposively selected as an instrumental case of effective Montessori teaching (Stake, 1995). Its Head Teacher was firstly a certified Montessori instructor with 32 years' of Montessori teaching experience. He was also an exemplary educator who had been awarded the Project E "Excellence in Education" Teacher Award in year 2003, an annual state-wide award that recognizes teachers for extraordinary contribution to teaching. This classroom was also selected because the school's tuition rate is well below the state average per pupil expenditure for K-6 public schools. This ensured that it was comparable to K-12 schools in the state.

\subsection{Participants}

The participants of this study were the Head Teacher and his assistant teachers. One of the assistant teachers had 4 years of teaching experience, while the other was a relatively new teacher who taught for a year in Montessori schools.

\subsection{Classroom Context}

This classroom had 28 students, aged 9 to 11 . Montessori classrooms are multi-age, usually comprising curriculum for three years of study (Lilliard, 2005). Therefore, the students would be the same as those in traditional elementary school grades 4-6. They completed a mandatory number of Works in each 16-week session including research projects in Physical 
Science, Natural Science, History, and Geography; book reports, and Math workbooks. A typical school-day was from 8:30 a.m. to 3:30 p.m. Students did their Works from 8:30 a.m. to 11:30 a.m. and took a short snack break at 9:45 a.m. before continuing with their Works until lunch time. In the afternoons, they attended Spanish and History classes in different class groupings, but re-gathered for clean-up duty before dismissal at 3:30 p.m. Two observation sessions were made of the classroom each week from 8:30 a.m. to 11:30 a.m. where they completed their Works. Discussion with teachers concluded that this best reflected the work patterns in a multi-age Montessori classroom.

\subsection{Data Collection}

Approval was obtained from the School Board, following which consent forms were circulated to teachers and parents of the students. General observations were made of classroom activities, but student motivation surveys were only administered on the students with parental consent. Data were collected from the following sources:

\subsubsection{Observations}

Nonparticipant naturalistic observation (Savenye \& Robinson, 2003) was used to collect data about the teachers' autonomy supportive strategies. This was because Cossentino (2006) recommended that naturalistic observations supported with ethnographic field notes better fitted data collection within the cultural context of the Montessori classroom which advocated student autonomy to work where they felt most comfortable. In our preliminary observations, the researchers also found that following the children around with video and audio equipment could disrupt their natural flow of activity, which threatened data validity. To avoid bias, field notes of the classroom activities were made in chronological order. A template was also set-up to focus data collection in the following aspects:

a) Types of learning activities;

b) Types of learning resources used; and

c) Types of teacher-and-student interactions/Student-and-student interactions,

The classroom observations were ended after a month as researchers found that the work patterns in this Montessori classroom were highly consistent, and there was adequate data saturation, as recommended by Creswell (1998).

\subsubsection{Post-observation interview}

To improve the reliability of the classroom observations, the learning activities, learning resources, teacher-student interactions, and student-student interactions recorded in the field notes were summarized and verified with the teachers in a post-observation interview. This was a form of member checking recommended by Creswell (1998). During this one-hour semi-structured focus-group interview, teachers were first asked to verify a summary list of learning activities, learning resources, teacher-student interactions, and student-student interactions recorded in field notes. They were then asked to describe their conceptions of student autonomy, and the types of classroom practices they used to support it. The notes of interview were recorded and sent to the teachers for verification via e-mail after the interview. 
The Head Teacher responded with additional comments and clarifications via e-mail.

\subsubsection{Surveys}

In addition to interviewing the teachers about their autonomy supportive practices, the researchers also administered a survey to collect corroborating information (Creswell, 1998) about the teachers' motivation styles. The Problems in Schools Questionnaire (Cai, Reeve, \& Robinson, 2002; The Motivators' Orientations Questionnaires, n.d.; Reeve et al., 1999) was administered to each teacher at the beginning of the study. To avoid bias to the teachers' instructional behaviors, the purpose of the questionnaire and survey results were not revealed until the end of the study. The questionnaire consisted of eight vignettes that described typical motivational problems exhibited by elementary-age students. Four responses were available for each vignette where each corresponded to one of four motivating styles: highly controlling, moderately controlling, moderately autonomy supportive, and highly autonomy supportive subscales. Teachers rated the 32 possible responses on a seven-point Likert-type scale where: 1 (very inappropriate), 4 (moderately appropriate), and 7 (very appropriate). The maximum possible score of 56 points for each motivational style was averaged across the eight vignettes. The average scores obtained for each motivational style were then compared to determine which was dominant. The higher the average score obtained, the more dominant that motivational style.

Another source of data collected to triangulate the effectiveness of the teachers' autonomy supportive practices was the student survey. The Academic Self-Regulation Questionnaire (Grolnick \& Ryan, 1987; Miserandino, 1996; The Self-Regulation Questionnaires, n.d.) was administered to the 10 students with parental consent for survey participation at both the beginning and end of the study to assess their level of motivation with respect to doing schoolwork. It consisted of 32 questions that measured four types of motivation for doing schoolwork as defined by Self-Determination Theory: External Regulation, Introjected Regulation, Identified Regulation and Intrinsic Motivation. Each question was scored on a four-point Likert-type scale where 1 (Not at all true), 2 (Not very true), 3 (Sort of true), and 4 (Very true). The average score of items measuring each motivation type was computed where the highest average score characterized students' predominant motivational tendency. Self-Determination Theory postulated that Integrated Regulation represents greater integration of external goals than Identified Regulation. However, it was not measured in the Academic Self-Regulation Questionnaire as Deci et al. (1991) assumed that elementary and middle school children were too young to achieve this level of integration with respect to school work.

\subsection{Data Analysis}

The following sections describe the methods for analyzing the qualitative and quantitative data collected.

\subsubsection{Qualitative Data}

The qualitative data collected from classroom observations and the teacher interview were analyzed with what Yin (2003) defined as theoretical models, or existing propositions about a 
phenomena. The three categories of autonomy support as defined by Stefanou et al. (2004) were initially used as the theoretical model to guide the interpretation of qualitative data, and to set-up the coding protocol. During this initial analysis, the researchers also found many instances of "controlling events". This was therefore included as a fourth category in the coding protocol (See Table 1).

Table 1. Coding protocol

\begin{tabular}{|l|l|}
\hline Category & Description \\
\hline Organizational autonomy support & $\begin{array}{l}\text { Give student choice to manage learning } \\
\text { environment e.g., choice of group members, } \\
\text { seating arrangement, and rules of work. }\end{array}$ \\
\hline Procedural autonomy support & $\begin{array}{l}\text { Give students choice over the form of their } \\
\text { work-e.g., how to display their projects, } \\
\text { materials, and resources to use. }\end{array}$ \\
\hline Cognitive autonomy support & $\begin{array}{l}\text { Give students ownership of the learning } \\
\text { process-e.g., solve problems independently, ask } \\
\text { questions, and voice opinions. }\end{array}$ \\
\hline Controlling events & $\begin{array}{l}\text { Events that deter students from being the origin or } \\
\text { source of their behavior- e.g., imposition of } \\
\text { directives, and restriction of choice. }\end{array}$ \\
\hline
\end{tabular}

After setting up the coding protocol, it was presented to the teachers as a form of member check (Creswell, 1998). The teachers agreed that it captured their autonomy supportive strategies and did not propose any further changes. This finalized protocol was then used to code all observation field notes and interview data. The coded observations field notes were then triangulated with teacher interviews as corroborating sources to derive the qualitative study results.

\subsubsection{Quantitative Data}

Data from the teacher and student surveys were analyzed using descriptive statistics. For the student surveys, the statistical differences between their pre and post-observation motivation ratings were further analyzed with paired sample $t$-tests.

\section{Results}

\subsection{Motivation Styles of Teachers}

The survey of teacher motivation styles found that all three teachers consistently scored the highest ratings for the Highly Autonomy Supportive motivation style ( $\mathrm{M}=5.79, \mathrm{SD}=0.76)$, as compared to the other motivation styles: Moderately Autonomy Supportive $(\mathrm{M}=3.58, \mathrm{SD}=$ 0.34), Moderately Controlling $(\mathrm{M}=2.88, \mathrm{SD}=0.38)$, Highly Controlling $(\mathrm{M}=2.00, \mathrm{SD}=0.00)$.

\subsection{Organizational autonomy support}

Students in this Montessori classroom typically began the day by completing a worksheet of Head Problems, or teacher-designed math and logic-related problems. It was observed that 
they had a high amount of organizational autonomy support as they could choose to work on these problems individually or in groups. They could also move around and work on each question with different people if they wanted to. A substantial level of self-initiated peer collaboration was observed. At the teachers' table, groups of students gathered to clarify their questions. They then returned to their desks and instructed others. At another worktable, a student was helping another check his solution.

Students were given about an hour to complete their Head Problems, following which they moved on to the Morning Work Period where they did their other Works. Organizational autonomy support was also observed during the Morning Work Period even though students were not subjected to a fixed time-table but chose the Works they wanted to do. Five or six students could be typing project reports on the computers while two or three others may be working on Math problems at their desks. A teacher could be searching for a book with two students in the library; while the others were engaged in individual feedback sessions. In one corner of the classroom, four or five students were observing the growth process of caterpillars bred by the teachers while pairs of students were working together on Science experiments in another corner. Both the teachers and students were observed to be enthusiastically engaged throughout the Morning Work Period with personal consultations and Works even though it stretched the entire morning.

Organizational autonomy support facilitated the formation of social relationships between the teachers, students, and among peers. The students were often observed to be giving each other support. For example, they taught each other how to use scanners and graphic software to prepare illustrations for their project. They were also involved in the orientation of new students by serving as mentors for visitors from the lower elementary class. The teachers made use of organizational autonomy support to legitimize social time for students as they acknowledged this as being "important". For example, they were not insistent that students should proceed immediately to their Works should they complete their Head Problems early. It was not uncommon to find students taking advantage of this. About 15 minutes before the official start time for the Morning Work Period, a pair at a work table shared a story while doodling a cartoon character on some paper. Those presenting their answers to the Head Problems wrote their answers on a transparency over some small talk. A few students gathered around a teacher and asked when she would expect the caterpillars being bred in the class to turn into butterflies; another group stood by the parakeet cage and laughed at the birds' antics.

\subsection{Cognitive autonomy support}

Cognitive autonomy support in this Montessori classroom was anchored upon the "research laboratory" model (Lillard, 2005) typical of Montessori schools. The teachers introduced research themes to students, and encouraged them to self-initiate projects through joint negotiation with both their teachers and parents. They felt that families should be involved as "they would know some things about kids that we don't that would help them learn better."

The teachers gave emphasis to using cognitive autonomy support as a means for encouraging independent problem-solving. Whenever students sought their help, they were rarely given 
direct answers. A teacher shared that she typically had students "reflect on other problems that they have previously done." If that failed, she will work through a few problems together with them. This concurred with classroom observations. In fact, the teachers used this approach consistently even when asked factual questions such as the spelling of a word. The student was handed a dictionary while the teacher observed and helped when he had difficulty.

Another example of cognitive autonomy support was that students had a "voice" to improve the work they did. For example, a Math problem assigned to students stated that: "A Sunkist soda contains $\mathrm{X}$ amount of caffeine. How many Hershey bars have the same amount of caffeine?" A student highlighted that information about the amount of caffeine in a Hershey bar was missing. Teachers asked if he could do something about it. He immediately went to research the information on the World Wide Web using one of the classroom computers while the other students continued with their Works. After several minutes, he happily pronounced the information to the class and resolved the issue successfully. The teachers felt that this allowed students a stake in their own learning, and helped them contribute to "building community".

\subsection{Procedural autonomy support}

By and large, the teachers had specific classroom practices that they required students to conform to, for example, how to cite references for their projects, how to staple an evaluation sheet to their Head Problems before handing it up. Students had some procedural autonomy support to design posters for showcasing their completed projects on the walls of the classroom. However, it did not emerge strongly throughout the study, as compared to cognitive autonomy support and organizational autonomy support.

\subsection{Controlling events}

Controlling events such as high stakes testing were not used in this Montessori classroom. Instead, students generated drafts for their projects that were given interim evaluations for quality of contents, mechanics, the number of errors made, and the number of attempts for revision. The process of revision ended when teachers appraised it as being the Last Draft, or the version considered as satisfactory. Teachers supported students' learning by spending a large proportion of their time in one-to-one feedback and coaching sessions with students. A meeting could sometimes take up to 45 minutes, and teachers were observed to have met individually with at least four students to provide feedback on their projects during each Morning Work Period. A teacher described this as an important time where "most of the teaching happens."

While the controlling events were not present in the form of high-stakes testing, it was, however, present in the form of behavior expectations. Teachers did not regard such controls as being undermining of student autonomy; but emphasized that it was necessary for maintaining students' motivation to engage in productive work. In fact, students' freedom to execute choice was a privilege that could be taken away if not used responsibly. For example, two students who chose to work together became side-tracked with chatting about 
unrelated topics. They were gently reminded to focus on their work. When the chatting persisted, they were expressly warned that their choice to work collaboratively would be taken away if they did not work productively. The students took the cue and regained focus on their work.

The teachers in this classroom suppressed criticism and engaged students to reflect upon their mistakes when they misbehaved. One day, some students left their cleanup duties for the previous day uncompleted. The teachers did not directly reprimand or punish the students even though they knew who was responsible. Instead, the problem was opened up for class discussion. The teacher reiterated their class' policy of "not ending the day until all the jobs are done". She then asked the class to discuss why this was a problem for them, and how they planned to resolve it. Students who were responsible immediately apologized and quickly proceeded to complete their cleanup duty. As a warning, other students were not allowed to work on computers until cleanup was finished. No overt blame from the other students was noticed except that some waited anxiously by the computer terminal they wanted to use. A loud cheer from the class was heard when those on duty pronounced them completed. Students rushed quickly to continue their Works on the computers. This process helped the students understand the rationale when limits were set on their behavior.

\subsection{Students' motivation for schoolwork}

The Academic Self-Regulation Survey was administered both before $(n=10$, Response rate= $35.7 \%)$ and after $(n=9$, Response rate $=32.1 \%)$ the classroom observations. The pre-observation rating for other motivation categories were: External Regulation $(\mathrm{M}=2.47$, $\mathrm{SD}=0.56)$, Introjected Regulation $(\mathrm{M}=3.03, \mathrm{SD}=0.48)$, Identified Regulation $(\mathrm{M}=3.13, \mathrm{SD}$ $=0.53)$, and Intrinsic Motivation $(\mathrm{M}=2.15, \mathrm{SD}=0.56)$. The corresponding post-observation ratings were: External Regulation $(\mathrm{M}=2.54, \mathrm{SD}=0.53)$, Introjected Regulation $(\mathrm{M}=2.88, \mathrm{SD}$ $=0.57)$, Identified Regulation $(\mathrm{M}=3.12, \mathrm{SD}=0.54)$, and Intrinsic Motivation $(\mathrm{M}=2.10$, $\mathrm{SD}=0.45)$.

These results show that Identified Regulation characterized students' predominant motivation style. They had a greater tendency to undertake learning activities because they perceived some personal value and identification with the learning goals ("because it is important to me to work on my classwork") rather than because they felt compelled by external factors ("because I'll get into trouble if I don't"). Students' motivational profile remained fairly consistent throughout the study as there were paired sample $t$-tests showed no significant differences between the pre and post observation ratings for each motivation category at $\alpha=0.05$.

\section{Discussion}

\subsection{Autonomy support is multi-dimensional}

Deci et al. (1991) postulated that intrinsic motivation cannot be developed without autonomy support. This study found that Montessori children mainly experienced organizational autonomy support and cognitive autonomy support. The former was aimed at developing their mastery for organizing work, while the latter fostered independent thinking. Effective 
autonomy support could be multidimensional, with each dimension influencing motivation perceptions differently (Katz \& Assor, 2007; Stefanou et al., 2004). This study points to the need to look beyond the mere provision of choice when supporting student autonomy.

\subsection{Relationships between autonomy support, competence and relatedness}

Empirical studies have found that student perceptions of teacher autonomy support were positively correlated with their competency perceptions (Hardre \& Reeve, 2003; Standage et al., 2005; Valas \& Sovik, 1993). In this study, teachers' cognitive autonomy support was targeted at fostering students' involvement and confidence for independent problem-solving. Their competency perceptions could have also been fostered by the project evaluation system that rewarded continual effort and improvement. While extant research has mainly studied how positive feedback fostered competency perceptions (Deci \& Ryan, 1985), this study points to the need for further analysis of how cognitive autonomy support influences student competency perceptions.

This study showed that organizational autonomy support resulted in a classroom structure that encouraged peer support, which fostered relatedness (Ryan \& Deci, 2002) or the formation of social relationships among students. In their two-year longitudinal study, Wentzel, Barry and Caldwell (2004) found that sixth graders with reciprocated friendships from classmates obtained higher GPAs in sixth grade, and reported lower emotional distress when they were in eighth grade. Organizational autonomy support also allowed teachers to establish time for personalized feedback and consultation with students, which fostered relatedness between teachers and students. Wentzel (1998) found that perceived support from teachers was a significant positive predictor of sixth graders' interest in class and interest in school, which were in turn significant predictors of these students' grades one year later.

Self-Determination Theory postulates that the three human needs of autonomy, competence, and relatedness foster intrinsic motivation. For autonomy support to be efficacious on student motivation, its corresponding influences on competency and relatedness should be considered.

\subsection{Autonomy support as a means of honoring student "voice"}

This study showed that teachers used autonomy support as a means to engage students' "voice" in their learning activities. Students participated in improving the work they did, and brainstorming solutions for classroom problems they faced. Autonomy support was therefore relevant to their personal learning goals (Assor et al., 2002; Katz \& Assor, 2007; Stefanou et al., 2004). McCombs (2004) found that when students perceived teachers as "honoring" their "voice", it had positive impact on their learning, motivation, and behavioral outcomes.

\subsection{Appropriate implementation of controlling events}

This study showed that Montessori children had "limited choice" (Lillard, 2005) as they cannot choose to engage in unproductive activities. When they did so, teachers imposed limits and controls on them. However, the teachers studied used what Koestner, Ryan, Bernieri, and Holt (1984) termed as an informational limit-setting approach where they 
acknowledged students' feelings, suppressed criticism, and explained rationales for control. The students surveyed consistently rated themselves as having Identified Regulation for doing school work. According to the Academic Self-Regulation Survey, this is the highest level of extrinsic motivation that precedes Intrinsic Motivation. While the response rate for the survey may have somewhat limited the comprehensiveness of the students' motivation profile, these results nevertheless indicate that student motivation may not necessarily be undermined when controlling events are implemented appropriately.

\subsection{Guidelines for Practice}

The Montessori classroom practices observed in this study lead us to suggest five guidelines for implementation of classroom autonomy support:

a) Use cognitive autonomy support to engage students in independent problem-solving.

b) Use cognitive autonomy support to engage students" "voice" so that personal relevance of schoolwork is fostered.

c) Foster student-to-student cooperation with organizational autonomy support.

d) Establish teacher-to-student cooperation by using organizational autonomy support to engage in personal feedback and consultation.

e) Suppress criticism and provide rationales when setting limits for children.

\section{Conclusion}

Autonomy support in the Montessori classroom studied was anchored upon an educational philosophy that emphasizes self-mastery and independence in students. In this case study, we reported observations of teaching strategies in a Montessori classroom designed to support student autonomy. While the generalizability of these results may be limited to this Montessori classroom, further studies of Montessori classrooms are needed to validate the five guidelines proposed. This study can be replicated in more Montessori classrooms within and outside the state of Indiana, USA. When replicating this study, researchers should consider using student interviews to provide additional insight about their perceptions of teacher motivation practices. This is one aspect that may not have been thoroughly explored in this study. Besides Montessori classrooms, these five guidelines should also be validated with exemplary teachers from traditional K-12 schools. Comparative studies of Montessori and traditional K-12 classroom practices can help to uncover the important contextual and systemic factors necessary for fostering teachers' practice of autonomy support. A deeper analysis of these areas can contribute to the design of classroom contexts that improve the intrinsic motivation of K-12 students for learning.

\section{Acknowledgement}

The authors would like to thank Mrs. Kathy Frick and Mrs. Laurie Carmody for their help with editing this manuscript.

\section{References}

Ames, C. (1992). Classrooms: Goals, structures, and student motivation. Journal of 
Educational Psychology, 84(3), 261-271.

Anderman, E. M., \& Maehr, M. L. (1994). Motivation and schooling in the middle grades. Review of Educational Research, 64(2), 287-309.

Assor, A., Kaplan, H., \& Roth, G. (2002). Choice is good, but relevance is excellent: Autonomy-enhancing and suppressing teacher behaviours predicting students' engagement in schoolwork. British Journal of Educational Psychology, 72(2), 261-278.

Assor, A., Kaplan, H., Kanat-Maymon, Y., \& Roth, G. (2005). Directly controlling teacher behaviors as predictors of poor motivation and engagement in girls and boys: The role of anger and anxiety. Learning and Instruction, 15(5), 397-413.

Cai, Y., Reeve, J., \& Robinson, D. T. (2002). Home schooling and teaching style: Comparing the motivating styles of home school and public school teachers. Journal of Educational Psychology, 94(2), 372-380.

Cordova, D. I., \& Lepper, M. R. (1996). Intrinsic motivation and the process of learning: Beneficial effects of contextualization, personalization, and choice. Journal of Educational Psychology, 88(4), 715-730

Cossentino, J. M. (2006). Big work: Goodness, vocation, and engagement in the Montessori Method. Curriculum Inquiry, 36(1), 63-92.

Creswell, J. W. (1998). Qualitative inquiry and research design. Thousand Oaks, CA: SAGE Publications.

Deci, E. L., \& Ryan, R. M. (1985). Intrinsic motivation and self-determination in human behavior. New York: Plenum Press.

Deci, E. L., \& Ryan, R. M. (2000). The "What" and "Why" of goal pursuits: Human needs and the self-determination of behavior. Psychological Inquiry, 11(4), 227-368.

Deci, E. L., Vallerand, R. J., Pelletier, L. G., \& Ryan, R. M. (1991). Motivation and education: The self-determination perspective. Educational Psychologist, 26(3/4), 325-346.

Duax, T. (1989). Preliminary report on the educational effectiveness of a Montessori school in the public sector. The NAMTA Journal, 14(2), 56-62.

Grolnick, W. S., \& Ryan, R. M. (1987). Autonomy in children's learning: An experimental and individual difference investigation. Journal of Personality and Social Psychology, 52(5), $890-898$.

Hainstock, E. (1997). The essential Montessori. USA: Penguin Books.

Hardre, P., L., \& Reeve, J. (2003). A motivational model of rural students' intentions to persist in, versus drop out of high school. Journal of Educational Psychology, 95(2), 347 - 356.

Harter, S. (1981). A new self-report scale of intrinsic versus extrinsic orientation in the classroom: Motivational and informational components. Developmental Psychology, 17(3), 300-312. 
Katz, I., \& Assor, A. (2007). When choice motivates and when it does not. Educational Psychological Review, 19(4), 429-442.

Koestner, R., Ryan, R. M., Bernieri, F., \& Holt, K. (1984). Setting limits on children's behavior: The differential effects of controlling vs. informational styles on intrinsic motivation and creativity. Journal of Personality and Social Psychology, 52(3), 233-248.

Lepper, M. R., Sethi, S., Dialdin, D., \& Drake, M. (1996 ). Intrinsic and extrinsic motivation: A developmental perspective. In S. S. Luthar, J. A. Burack, D. Cicchetti \& J. R. Weisz (Eds.), Developmental psychopathology: Perspectives on adjustment risk and disorder (pp. 23-50). New York: Cambridge University Press.

Lillard, A. S. (2005). Montessori - The science behind the genius. New York: Oxford University Press.

Manouchehri, A. (2004). Implementing mathematics reform in urban school: A study of the effect of teachers' motivation style. Urban Education, 39(5), 472 - 508.

McCombs, B. L. (2004). The learner-centered psychological principles: A framework for balancing a focus on academic achievement with a focus on social and emotional learning needs. In J. E. Zins, R. E. Weissberg, M. C. Wang \& H. J. Walberg (Eds.), Building academic success on social and emotional learning: What does the research say? (pp. 23-39). New York: Teachers College Press.

Miserandino, M. (1996). Children who do well in school: Individual differences in perceived competence and autonomy in above-average children. Journal of Educational Psychology, 88(2), 203-214.

Montessori, M. (1964). The Montessori method. Massachusetts: Robert Bentley Inc.

Rathunde, K. R., \& Csíkszentmihályi, M. (2005). Middle school students' motivation and quality of experience: A comparison of Montessori and traditional school environments. American Journal of Education, 111, 341-371.

Reeve, J., Bolt, E., \& Cai, Y. (1999 ). Autonomy supportive teachers: How they teach and motivate students. Journal of Educational Psychology, 91(3), 537 - 548.

Reynolds, P. L., \& Symons, S. (2001). Motivational variables and children's text search. Journal of Educational Psychology, 93(1), 14-22.

Ryan, R. M., \& Connell, J. P. (1989). Perceived locus of casuality and internalization: Examining reasons for acting in two domains. Journal of Personality and Social Psychology, 57(5), 749-761.

Ryan, R. M., \& Deci, E. L. (2000). Intrinsic and extrinsic motivations: Classic definitions and new directions. Contemporary Educational Psychology, 25(1), 54-67.

Ryan, R. M., \& Deci, E. L. (2002). An overview of Self-Determination Theory: An organismic-dialectical perspective. In E. L. Deci \& R. M. Ryan. (Eds.), Handbook of self-determination research (pp. 3-36). Rochester, NY: The University of Rochester Press. 


\section{Macrothink

Savenye, W.C.., \& Robinson, R. S. (2003). Qualitative research issues and methods: An introduction for educational technologists. In D.H. Jonassen (Eds), Handbook of research for educational communications and technology (pp. 1045-1071). New York: Macmillan.

Stake, R. E. (1995). The art of case study research. Thousand Oaks, CA: SAGE Publications.

Standage, M., Duda, J. L., \& Ntoumanis, N. (2005 ). A test of self-determination theory in school physical education. British Journal of Educational Psychology, 75(3), 411-433.

Stefanou, C. R., Preencevich, K. C., DiCintio, M., \& Turner, J. C. (2004). Supporting autonomy in the classroom: Ways teachers encourage student decision making and ownership. Educational Psychologist, 29(2), 97-110.

The Motivators' Orientations Questionnaires (n.d.). Problems in Schools Questionnaire. Retrieved September 8, 2009, [Online] Available: http://www.psych.rochester.edu/SDT/measures/moq_pis_scale.php

The Self-Regulation Questionnaires. (n.d.). Academic Self-Regulation Questionnaire. $\begin{array}{llll}\text { Retrieved } & \text { September } & \text { [Online] Available: }\end{array}$ http://www.psych.rochester.edu/SDT/measures/SRQ_academic.php

Urdan, T., \& Turner, J. C. (2005). Competence motivation in the classroom. In A. J. Elliott \& S. C.S. Dweck (Eds.), Handbook of competence and motivation (pp. 297-317). New York: The Guilford Press.

Valas, H., \& Sovik, N. (1993). Variables affecting students' intrinsic motivation for school mathematics: Two empirical studies based on Deci and Ryan's theory on motivation. Learning and Instruction, 3(4), 281-298.

Vansteenkiste, M., Lens, W., \& Deci, E. L. (2006). Intrinsic versus extrinsic goal contents in self-determination theory: Another look at the quality of academic motivation. Educational Psychologist, 41, 19-31.

Wentzel, K. R. (1998). Social relationships and motivation in middle school: The role of parents, teachers, and peers. Journal of Educational Psychology, 90(2), 202-209.

Wentzel, K. R., Barry, C. M., \& Caldwell, K. A. (2004). Friendships in middle school: Influences on motivation and school adjustment. Journal of Educational Psychology, 96(2), 195-203.

Yin, R. K. (2003). Analyzing case study evidence. In Case study research: Design and methods (pp. 109-140). California: Sage Publications. 